\title{
Penentuan Waktu Standar Pada Proses Packaging Kerupuk (Studi Kasus: UKM Kerupuk Cabe Bintang Purnama)
}

\author{
Ade Irma Putri ${ }^{1}$, Fitra ${ }^{2}$, Jhon \\ Suarlin $^{3}$ \\ ${ }^{1)}$ Program Studi Teknik Industri, Sekolah \\ Tinggi Teknologi Dumai \\ Jl. Utama Karya Bukit Batrem II \\ Email: adeirmaputristt@gmail.com; \\ famukhtyfitra@gmail.com \\ john_suarlin@yahoo.co.id
}

\begin{abstract}
ABSTRAK
Usaha kecil menengah (UKM) merupakan suatu bentuk usaha yang didirikan berdasarkan inisiatif sesorang yang dapat menciptakan lapangan bagi masyarakat luas. Salah satu UKM yang ada di Kota Dumai yang bergerak di bidang makanan yaitu UKM Kerupuk Cabe Bintang Purnama. Penelitian ini bertujuan untuk mengetahui waktu standar bagi pekerja untuk menyelesaikan suatu kegiatan hingga menghasilkan produk dengan kemasan berat 10 gram, 50 gram, 150 gram dan 350 gram, penelitian ini dilakukan dengan menggunakan metode stopwatch time study dimana metode yang digunakan untuk menghitung waktu kerja operator dan produksi dengan metode kerja yang terbaik pada proses packaging dari mulai pengerjaan memasukkan kerupuk hingga pada proses sealing kerupuk. Hasil dari penelitian ini adalah waktu standar untuk proses pembungkusan kerupuk cabe dengan ukuran 10 gram diperoleh waktu 13,62 detik, ukuran 50 gram diperoleh waktu 27,02 detik, ukuran 150 gram diperoleh waktu 27,91 detik, dan ukuran 350 gram diperoleh waktu 45,66 detik. Waktu standar untuk proses pengeleman kerupuk cabe dengan ukuran 50 gram diperoleh waktu 06,11 detik, ukuran 150 gram diperoleh waktu 11,86 detik, dan ukuran 350 gram diperoleh waktu 18,77 detik. Berdasarkan hasil penelitian maka untuk pengingkatan dan mengefisienkan waktu kerja dapat dilakukan perbaikan atau peninjauan kembali metode kerja yang akan dilakukan.
\end{abstract}

Kata kunci: Packaging Kerupuk Cabe, Stopwatch Time Study, Waktu Standar

\section{ABSTRACT}

Usaha Kecil Menengah (UKM) is a form of business that is founded on the initiative of someone who can create a workfield for the wider community. One of the UKM in Dumai City which is engaged in the food sector is UKM Purnama Bintang. Based on the above problems, this research aims to determine the standard time for workers to complete a process to produce the products of chilli chips with various types of packaging. This research was conducted using the stopwatch time study method. The results of this research are the standard time for the process of wrapping chilli chips with a size of 10 grams, the time is 13,62 seconds, the wrapping chilli chips with a size of 50 grams the time is 27,02 seconds, the wrapping of chilli chips with a size of 150 grams the time is 27,91 seconds. wrapping chilli chips with a size of 350 grams the time is 45,66 seconds. standard time for the process of sealing the packages of chilli chips with a size of 50 grams, the time is 06,11 seconds, and the sealing process of chilli chips packages with a size of 150 grams takes 11,86 seconds. And the standard time for the sealing process for chilli chips packages with a size of 350 grams is 18,77 seconds. Based on the results of the research, to improve and streamline working time, improvements or work methods can be reviewed.

Keywords: Chilli Cracker Packaging, Standard Time, Stopwatch Time Study 


\section{Pendahuluan}

Usaha kecil menengah (UKM) merupakan suatu bentuk usaha yang didirikan berdasarkan inisiatif sesorang yang dapat menciptakan lapangan pekerja bagi masyarakat luas. Usaha kecil yaitu kegiatan ekonomi yang dilakukan bertujuan untuk memproduksi barang/jasa yang memiliki nilai guna yang lebih tinggi. Kota Dumai merupakan wilayah dengan banyaknya terdapat UKM, mulai dari sektor makanan, jasa dan perdagangan yang berkembang pesat di Dumai. Salah satu UKM dalam sektor makanan/jajanan yang ada di Kota Dumai yaitu olahan dari singkong seperti salah satunya kerupuk cabe yang menjadi ciri khas dari Kota Dumai itu sendiri.

UKM kerupuk cabe Bintang Purnama merupakan UKM yang mengolah bahan mentah singkong menjadi produk jajanan seperti kerupuk cabe. UKM ini memproduksi cemilan rumahan yang dipasarkan baik di Kota Dumai maupun di luar Kota Dumai. UKM kerupuk cabe Bintang Purnama ini dapat beroperasi selama 10,5 jam kerja untuk setiap harinya. Waktu kerja dalam dunia kerja merupakan salah satu faktor yang penting dan perlu mendapat perhatian dalam sistem produksinya. Waktu berperan dalam menentukan produktivitas kerja serta dapat menjadi tolak ukur menjadi bahan evaluasi dalam menentukan metode kerja yang terbaik dalam menyelesaikan sebuah pekerjaan yang bermanfaat bagi pengefisienan kerja, keamanan dan kenyamanan kerja bagi operator.

Penelitian ini dilakukan dengan metode stopwatch time study di mana penelitian ini bertujuan untuk mengetahui waktu standar bagi pekerja untuk menyelesaikan suatu kegiatan hingga menghasilkan produk dengan berbagai jenis kemasan. Berdasarkan latar belakang yang telah diuraikan maka peneliti tertarik untuk mengadakan penelitian dengan judul "Penentuan Waktu Standar Pada Proses Packaging Kerupuk Studi Kasus (UKM Kerupuk Cabe Bintang Purnama)" dengan menggunakan metode stopwatch time study.

\section{Metode Penelitian}

Penelitian ini dilakukan di UKM Kerupuk Cabe Bintang Purnama yang berlokasi di Jln Raja Ali Haji, Gang Rindu Darat, Kelurahan Purnama, Kecamatan Dumai Barat, Kota Dumai. Waktu penelitian dilakukan mulai dari bulan april hingga september 2020. Penentuan sampel dalam penelitian ini menggunakan metode stopwatch time study. Sampel dalam penelitian ini yaitu 2 orang pekerja sebagai sampel dengan menggunakan 280 data pengamatan dengan 4 jenis ukuran kemasan yaitu 10 gram dengan 40 pengamatan, 50 gram dengan 40 pengamatan pada proses memasukkan kerupuk ke dalam kemasan dan 40 pengamatan untuk proses sealing kemasan, 150 gram dengan 40 pengamatan pada proses memasukkan kerupuk ke dalam kemasan dan 40 pengamatan untuk proses sealing, dan ukuran 350 gram dengan 40 pengamatan pada proses memasukkan kerupuk ke dalam kemasan dan 40 pengamatan pada proses sealing kemasan. Penerapan waktu stopwatch time study pada penelitian ini untuk menentukan waktu standar proses packaging kemasan kerupuk.

1. mengelompokan data pengamatan dalam bentuk sub grup yang masing masing berisi 5 nilai pengukuran yang diperoleh secara berturut-turut dan hitung harga rata-ratanya.

2. Hitung rata-rata dari harga rata-rata subgrup dengan:

$$
\bar{X}=\frac{\sum \mathrm{Xi}}{\mathrm{k}}
$$

3. Hitung standar deviasi sebenarnya dari waktu penyelesaian dengan: 


$$
\sigma=\sqrt{\frac{\sum(\mathrm{Xj}-\mathrm{X})^{2}}{\mathrm{~N}}}
$$

4. Hitung standar deviasi dari distribusi harga rata-rata subgroup dengan:

$$
\sigma \overline{\bar{x}}=\sigma / \sqrt{n}
$$

5. Tentukan batas kendali atas (BKA) dan batas kendali bawah (BKB) dengan:

$$
\mathrm{BKA}=\overline{\overline{\mathrm{x}}}+2 \sigma \overline{\mathrm{x}}
$$

$\mathrm{BKB}=\overline{\overline{\mathrm{x}}}-2 \sigma \overline{\mathrm{x}}$

6. Uji Tingkat Ketelitian dan Keyakinan

$$
\mathrm{N}^{\prime}=\left[\frac{\mathrm{k} / \mathrm{s} \sqrt{\mathrm{N} \sum \mathrm{xj}^{2}-\left(\sum \mathrm{xj}\right)^{2}}}{\sum x j}\right]^{2}
$$

di mana: $\mathrm{N}$ adalah jumlah pengukuran yang telah dilakukan.

$\mathrm{N}$ ' adalah jumlah pengukuran yang diperlukan

7. Hitung waktu siklus, yang tidak lain adalah waktu penyesuaian rata-rata selama pengukuran:

$$
\mathrm{W}_{\mathrm{S}}=\frac{\sum \mathrm{x}_{\mathrm{i}}}{\mathrm{N}}
$$

8. Hitung waktu normal dengan:

$$
\mathrm{W}_{\mathrm{n}}=\mathrm{W}_{\mathrm{s}} \times \mathrm{p}
$$

9. Menghitung waktu baku dengan:

$\mathrm{Wb}=\mathrm{Wn} \times(1+$ all $)$

\section{Hasil dan Pembahasan}

\section{A. Pengumpulan Data}

Pengumpulan data dalam penelitian ini dengan menggunakan metode stopwatch time study. Pengumpulan data dilakukan dengan menggunakan stopwatch, alat tulis, lembaran data pengamatan (peneliti langsung mengambil data kelapangan) dan kamera. Pengamatan dilakukan sebanyak 280 data pengamatan dengan 4 jenis ukuran kemasan kerupuk cabe yaitu 10 gram, 50 gram, 150 gram dan 350 gram, dimana pada proses memasukan kerupuk ke plastik memiliki 4 layout dan pada proses sealing terdapat 3 layout tergantung jenis ukuran dari masing-masing kerupuk. Pengamatan terhadap masing-masing operator dalam setiap bagian (bagian memasukkan ke plastik dan bagian sealing) yang berjumlah 2 orang operator.

\section{B. Pengolahan Data}

\section{Layout Packaging Kerupuk 350 Gram}

Pelaksanaan pengukuran kerja pada proses packing kerupuk cabe 350 gram dengan uraian wadah, timbangan, plastik bungkus, keranjang hasil yang dapat di lihat pada Gambar 1. 


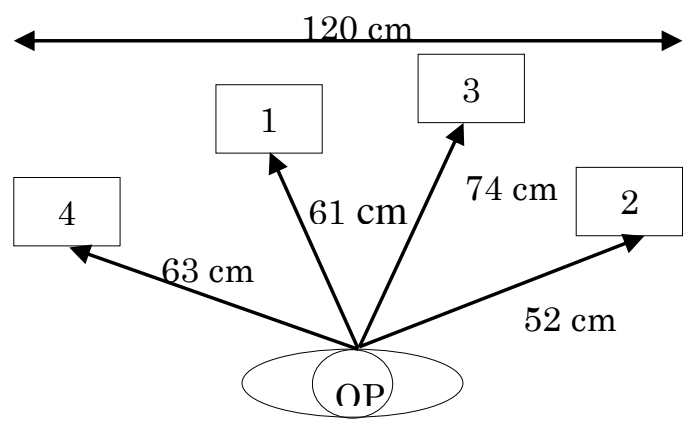

Gambar 1. Layout Packing Kerupuk 350 gram

\section{Pekerjaan Packing 350 Gram}

Hasil pengamatan yang dilakukan, maka data pengamatan pada operator kedua pada layout 4 dapat disubgrup seperti pada Tabel 1.

Tabel 1. Pengukuran Pendahuluan Layout 4 Operator 2

\begin{tabular}{clllllr}
\hline \multicolumn{7}{c}{ Subgrup Operator 2 (Mbah Simis) } \\
Subgrup Ke & \multicolumn{7}{c}{ Waktu Penyesuaian Berturut-turut (detik) } & \multirow{2}{*}{ Rata-rata } \\
& 1 & 2 & 3 & 4 & 5 & \\
\hline 1 & 38,16 & 37,56 & 38,95 & 35,90 & 30,35 & 36,18 \\
2 & 30,04 & 35,59 & 36,02 & 30,47 & 39,23 & 34,27 \\
3 & 35,25 & 30,92 & 31,32 & 31,05 & 32,91 & 32,29 \\
4 & 42,40 & 37,42 & 36,27 & 31,63 & 27,35 & 35,01 \\
5 & 41,15 & 38,11 & 26,67 & 31,23 & 30,53 & 33,54 \\
6 & 31,82 & 27,76 & 35,47 & 28,55 & 34,53 & 31,63 \\
7 & 33,86 & 31,04 & 35,20 & 36,83 & 38,33 & 35,05 \\
8 & 32,86 & 31,26 & 31,23 & 31,05 & 30,17 & 31,31 \\
Jumlah & & & & & & 269,29 \\
\hline
\end{tabular}

Sumber: Pengolahan Data, 2020

a. Rata-rata dari harga rata-rata subgrup

Nilai rata-rata dari harga rata-rata subgrup dapat dihitung sebagai berikut:

$=\frac{269,29}{8}=33,66$ menit

b. Standar deviasi sebenarnya dari waktu penyelesaian

Standar deviasi sebenarnya dari waktu penyelesaian dapat dihitung sebagai berikut:

$$
\begin{aligned}
& =\sqrt{\frac{(38,16-33,66)^{2}+(37,56-33,66)^{2}+(38,95-33,66)^{2}+\ldots+(30,17-33,66)^{2}}{40-1}} \\
& =3,88 \text { detik }
\end{aligned}
$$

c. Standar deviasi dari distribusi harga rata-rata subgrup berikut:

Standar deviasi sebenarnya dari waktu penyelesaian dapat dihitung sebagai $=\frac{3,88}{\sqrt{5}}=\frac{3,88}{2,23}=1,74$ menit 


\section{d. Mencari BKA dan BKB}

Pengujian ketelitian keseragaman data bertujuan untuk mengetahui data yang diambil memiliki keseragaman data atau tidak dengan menghitung batas kontrol atas dan batas kontrol bawah (BKA dan BKB) dengan menggunakan Rumus 4 dan Rumus 5.

$$
\begin{aligned}
& \mathrm{BKA}=\overline{\overline{\mathrm{x}}}+2 \sigma_{\mathrm{x}}=33,66+(2 \times 1,74)=37,14 \text { detik } \\
& \mathrm{BKB}=\overline{\overline{\mathrm{x}}}-2 \sigma_{\mathrm{x}}=33,66-(2 \times 1,74)=30,19 \text { detik }
\end{aligned}
$$

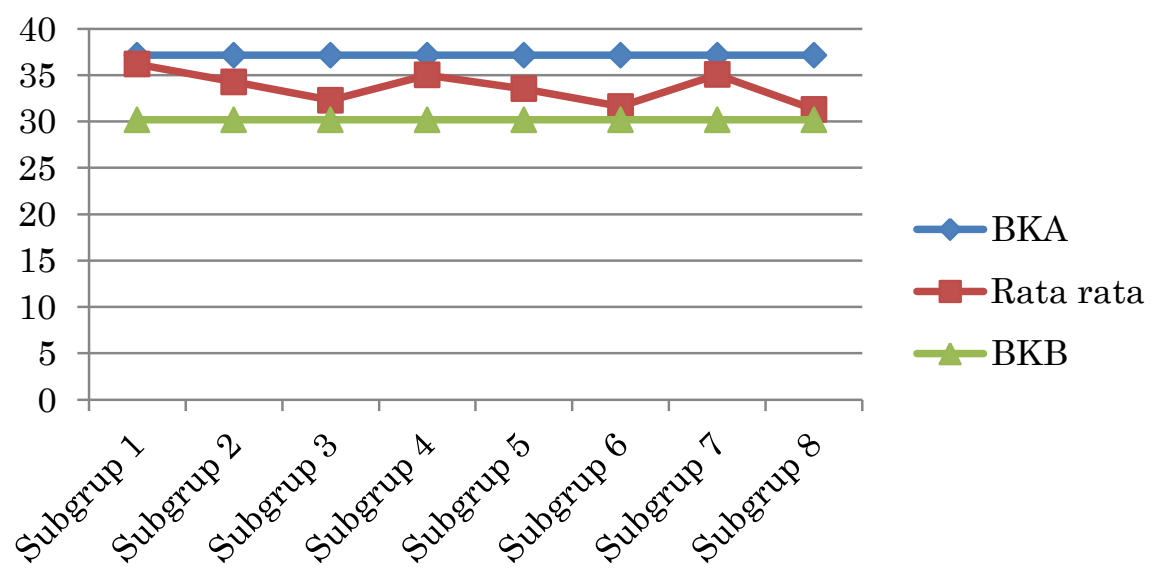

Gambar 2. Grafik Operator 2 Layout 4

Sumber: Pengolahan Data, 2020

e. Jumlah banyaknya pengukuran yang diperlukan

Apabila tingkat ketelitian (s) yang diinginkan sebesar 5\% =0,05 dan tingkat keyakinan (k) 95\% = 2 Uji kecukupan data dapat dihitung sebagai berikut:

$$
\begin{aligned}
& N^{\prime}=\left(\frac{40 \sqrt{40\left(\left(38,16+\ldots+(30,17)^{2}\right)-(38,16+\ldots+30,17)^{2}\right.}}{(38,16+\ldots+30,17)}\right)^{2} \\
& N^{\prime}=20,77 \text { pengamatan }
\end{aligned}
$$

f. Menghitung waktu siklus

Hitung waktu siklus merupakan waktu penyelesaian rata-rata selama pengukuran dapat dihitung sebagai berikut:

$$
\mathrm{Ws}=\frac{1346,44}{40}=33,66 \text { detik }
$$

i. Menghitung waktu normal

Diketahui rating factor (RF) untuk operator berdasarkan Westinghouse seperti pada Tabel 2.

Tabel 2. Rating Factor Operator Pengemasan 350 Gram

\begin{tabular}{lrrcr}
\hline \multirow{2}{*}{ No } & \multirow{2}{*}{ Faktor } & \multicolumn{3}{c}{ Mbah Simis (62 Tahun) } \\
& & Kelas & Lambang & Penyesuaian \\
\hline \multirow{2}{*}{1} & Keterampilan & Good & C1 & $+0,06$
\end{tabular}


Total

\begin{tabular}{|c|c|c|c|}
\hline 2 Usaha & Good & $\mathrm{C} 1$ & $+0,05$ \\
\hline Kondisi kerja & Good & $\mathrm{C}$ & $+0,02$ \\
\hline 4 Konsistensi & Good & $\mathrm{C}$ & 0,01 \\
\hline$g$ factor & & & $\begin{array}{l}0,14 \\
1,14\end{array}$ \\
\hline
\end{tabular}

Sumber: Pengolahan Data, 2020

Jadi, $\mathrm{p}=(1+0,14)=1,14$

Tabel 2 menunjukkan rating factor untuk operator kedua yang memiliki keterampilan good dengan nilai $+0,06 \%$; usaha good dengan nilai $+0,05 \%$; kondisi kerja good dengan nilai $+0,02$; konsistensi good $+0,1 \%$ dengan nilai. Diperoleh RF sebesar $+0,86 \%$, maka didapatkan faktor penyesuaian (p) sebesar 1,14 .

$\mathrm{Wn}=\mathrm{Ws} \times \mathrm{p}$

$\mathrm{Wn}=33,66 \times 1,14=38,37$ detik

j. Menghitung waktu baku

Kelonggaran (allowance) untuk operator kedua berdasarkan faktor-faktor yang berpengaruh dapat dilihat pada Tabel 3.

Tabel 3. Penentuan Besar Kelonggaran Operator 2 Layout 4

\begin{tabular}{llr}
\multicolumn{1}{c}{ Point } & \multicolumn{1}{c}{ Faktor } & $\begin{array}{r}\text { Kelonggaran } \\
(\%)\end{array}$ \\
\hline Tenaga yang dikeluarkan & Duduk & 6 \\
Sikap kerja & Bekerja duduk, ringan & 0 \\
Gerakan kerja & Normal & 0 \\
Kelelahan mata & Pandangan yang terputus-putus & 6 \\
Keadaan suhu tempat kerja & Normal & 3 \\
Keadaan atmosfer & Baik & 0 \\
Keadaan lingkungan yang & Bersih, sehat, cerah dengan & 0 \\
baik & kebisingan rendah & 4 \\
Kelonggaran untuk kebutuhan pribadi wanita & 19 \\
Total allowance & & \\
\hline Sumber Pengolan
\end{tabular}

Sumber: Pengolahan Data, 2020

Maka dari nilai-nilai tersebut didapatkan nilai waktu baku sebagai berikut:

$\mathrm{Wb}=\mathrm{Wn}(1+A l l)$

$\mathrm{Wb}=38,37 \times(1+0,19)=45,66$ detik

Sehingga waktu baku yang dibutuhkan operator kedua untuk menyelesaikan proses pembungkusan dalam siklus produksi sebesar 45,66 detik.

\section{Kesimpulan}

Berdasarkan analisis dan pembahasan yang telah dilakukan maka, diperoleh kesimpulan waktu standar yang diperlukan oleh pekerja untuk proses packaging kerupuk cabe pada proses pembungkusan kerupuk cabe:
a. Ukuran 10 gram diperoleh waktu 13,62 detik
b. Ukuran 50 gram diperoleh waktu 27,02 detik
c. Ukuran 150 gram diperoleh waktu 27,91 detik 
d. Ukuran 350 gram diperoleh waktu 45,66 detik

Untuk waktu standar yang diperlukan oleh pekerja pada proses pengeleman kerupuk cabe:

a. Ukuran 50 gram diperoleh waktu 06,11 detik

b. Ukuran 150 gram diperoleh waktu 11,86 detik

c. Ukuran 350 gram diperoleh waktu 18,77 detik

\section{Saran}

Adapun saran yang dapat penulis berikan, sesuai metode dan proses kerja yang penulis amati berjalan sesuai dengan prosedur yang diberikan oleh pihak UKM yaitu:

1. Adapun untuk meningkatkan dan mengefisienkan waktu kerja di bagian packaging perlu dilakukan perbaikan atau peninjauan kembali metode kerja yang akan dilakukan.

2. Menambah jumlah tenaga kerja di bagian packaging agar proses pengerjaan dapat lebih efektif dan efesien.

3. Memperhatikan kebersihan pekerja saat melakukan pekerjaan seperti mengenakan masker, sarung tangan dan penutup kepala agar selama proses pekerjaan lebih higenis.

\section{Daftar Pustaka}

Arif, M., Zamista, A.A., dan Firmansyah, (2021), Pengukuran Waktu Kerja Pada Proses Pembuatan Kerupuk Cabe Maisatun Purnama Dumai, Jurnal ARTI (Aplikasi Rancangan Teknik Industri), VOL.16 NO 1 (2021) Desember 2020 - Mei 2021, Hal: $79-85$

Bridger, R.S., 2009, Introduction to Ergonomics 3rd Edition, USA: CRC Press.

Cahyawati, A.N., dan Prastuti, N.D., 2018, Analisis Pengukuran Waktu Kerja pada Proses Packaging Kasa Hidrofil Menggunakan Metode Stopwatch Time Study, Seminar Nasional Inovasi dan Aplikasi Teknologi di Industri, ISSN: 2085-4218, Vol. 7 (1), Hal: 256-260.

Cahyawati, A.N., Munawar, F.A., Anggraini, A., dan Rizky, D.A., 2018, Analisis Pengukuran Kerja dengan Menggunakan Metode Stopwatch Time Study, Seminar Nasional Teknologi dan Rekayasa, ISSN: 2527-6042, Vol. 6 (2), Hal: 106-112.

Febrina, W., Suarlin, J., dan Mawariska, A.A., (2021), Waktu Standar Surat Izin Bongkar Palm Kernel Expeller Di Pt. Xyz Dumai, Jurnal ARTI (Aplikasi Rancangan Teknik Industri), VOL.16 NO 1 (2021) Desember 2020 - Mei 2021, Hal: 65-71

Fitra., Mesra, T., dan Melliana., 2020, Perhitungan Waktu Baku dengan Metode Work Sampling pada SPBU XYZ di Kota Dumai, Jurnal Teknik Industri, ISSN: 14104520, Vol. 15 (3), Hal: 283-286.

Fitriadi., Putra, G., dan Abdullah, A., 2018, Penentuan Jumlah Tenaga Kerja Optimal Melalui Pengukuran Waktu Baku dengan Menggunakan Metode Stopwatch Time Study pada Pembuatan Batu Bata Press (Studi Kasus UD. Tiga Setangkai Kabupaten Nangan Raya), Jurnal Optimalisasi, ISSN: 2477-5479, Vol. 4 (3), Hal: 62-69. 
Iridiastadi, H., dan Yassierli, 2014, Ergonomi Suatu Pengantar, PT Remaja Rosdakarya, Bandung.

Kroemer, K. H. E., Kroemer, H. B., dan Kroemer, K. E., 2004, Ergonomics: How Design for Ease and Efficiency, New Jersey, Prentice Hall.

Mesra, T., Fitra., dan Achmad, A, P., 2016, Perhitungan Waktu Standar Uji Sampel Refined Bleached Deodorized Palm Oil, Jurnal Teknik imdustri, ISSN: 25413023, Vol., Hal: 84-94.

Muzakir., Irawan, H.T., dan Pamungkas, L., 2018, Pengukuran Waktu Waktu Kerja Karyawan Bengkel Toyota PT. Dunia Barusa di Kota Banda Aceh, Jurnal Optimalisasi, ISSN: 2502-0501, Vol. 4 (1), Hal: 21-29.

Saputra, J., Hafrida, E., dan Musri, M., (2021), Pengukuran Waktu Kerja Berbasis Stopwatch Time Study Dan Analisis Keselamatan Kesehatan Kerja Pada Pabrik Tahu Sukri Bukit Batrem Dumai, Jurnal ARTI (Aplikasi Rancangan Teknik Industri), VOL.16 NO 1 (2021) Desember 2020 - Mei 2021, Hal: 86-93

Susanti, E., Palit, H, C., dan Aysia, D, A, Y., 2015, Perhitungan Waktu Baku dengan Berbagai Variasi Produk di PT. X, Jurnal Titra, ISSN: 2465-4563, Vol. 3 (2), Hal: 303-310

Sutalaksana, I.Z., Anggawisastra, R., dan Tgakraatmadja, J.H., 2006, Teknik Perancangan Sistem Kerja, ITB, Bandung. 